\title{
Children's Interpretation of Ambiguous wh-Adjuncts in Mandarin Chinese
}

\author{
Jing Li and Peng Zhou* \\ Department of Foreign Languages and Literatures, Child Cognition Lab, Tsinghua University, Beijing, China
}

The paper reports two studies investigating children's acquisition of the wh-adjunct zenme in Mandarin. Unlike other Mandarin wh-words that correspond to a single meaning, zenme can be used to question either the manner or the cause of an event. Study 1 explored whether children understand that zenme is ambiguous between a causal and a manner reading. Study 2 examined whether they can use syntactic cues to disambiguate the two readings. The findings show that children as young as 4 years of age access both the manner and the causal reading, but they prefer the former

OPEN ACCESS

Edited by:

Xiaolin Zhou,

Peking University, China

Reviewed by:

Zhenguang Cai,

University College London,

United Kingdom

Siying Liu,

Shanghai International Studies

University, China

*Correspondence:

Peng Zhou

zhoupeng1892@mail.tsinghua.edu.cn

Specialty section:

This article was submitted to

Language Sciences,

a section of the journal

Frontiers in Psychology

Received: 02 April 2020

Accepted: 29 June 2020

Published: 28 July 2020

Citation:

Li J and Zhou P (2020) Children's Interpretation of Ambiguous

wh-Adjuncts in Mandarin Chinese.

Front. Psychol. 11:1781.

doi: 10.3389/fpsyg.2020.01781 over the latter. Children exhibit a developmental trajectory when acquiring the mapping relations between the syntactic positions of zenme and its corresponding semantic interpretations: 5-year-olds can use syntactic cues to disambiguate the two readings; 3-year-olds, however, are still in the stage of working out how the syntactic positions are mapped onto the relevant semantic interpretations; the critical change occurs at around 4 years of age. The implications of the findings were then discussed in relation to the two major competing theories of child language acquisition.

Keywords: Wh-adjuncts, syntactic cues, semantic interpretations, Mandarin Chinese, child language

\section{INTRODUCTION}

There are two major competing approaches to child language acquisition: the UG (Universal Grammar)-based approach and the usage-based approach. The UG-based approach is based on the theory of Universal Grammar by Noam Chomsky (1965). This approach emphasizes the discrepancy between language input and the linguistic knowledge children acquire in the first few years of life. In other words, the approach acknowledged the fact that the linguistic knowledge acquired by young children vastly exceeds the linguistic input they have been exposed to. To account for the discrepancy, the UG-based approach proposes that children are born with some abstract linguistic knowledge that guides their language acquisition. These innately specified linguistic constraints constitute the initial state of language acquisition, and hence form the basis on which knowledge of language develops (Chomsky, 1975, 1980). On this approach, sentences are hierarchically structured, and the interpretations that can be assigned to sentences are dependent on the abstract structural constraints. Guided by these constraints, children are expected to acquire language in a relatively rapid and effortless manner (Chomsky, 1980; Crain and Nakayama, 1987; Crain and Pietroski, 2001; Crain et al., 2017). 
The usage-based approach, in particular the one represented by the constructivist theory, proposes that our grammatical knowledge consists in an inventory of different constructions learned from the input. Each construction is associated with a particular function, and children learn different constructions alongside their functions in the context (Goldberg, 2003, 2006; Ambridge and Lieven, 2011). This approach denies that children are born with innate linguistic knowledge, and claims that children learn language by witnessing language in use in linguistic contexts. On this approach, children acquire linguistic knowledge by attending to linguistic input and by using domain-general learning mechanisms, such as imitation, analogy and distributional analysis (Bybee, 2001; Pullum and Scholz, 2002; Tomasello, 2006; Lieven and Tomasello, 2008; Saxton, 2010). This approach expects that children acquire language in a more gradual and piecemeal fashion and that the acquisition of particular linguistic constructions relies heavily on the specific language to which a particular child is exposed (Tomasello, 2000, 2003). So one basic assumption following the usagebased approach is that more frequent constructions in the language input are acquired earlier than less frequent ones (Tomasello, 2000, 2003, 2006; Lieven and Tomasello, 2008; Ambridge and Lieven, 2011).

This paper reports two experimental studies on young children's acquisition of two types of zenme (roughly corresponding to English how) questions in Mandarin Chinese, with an attempt to show how theoretical analyses of linguistic structures could raise interesting questions for child language acquisition, and how data from child language acquisition can, in turn, inform linguistic theories.

\section{ZENME QUESTIONS IN MANDARIN}

Mandarin zenme, roughly corresponding to English how, is a commonly used interrogative adverb. Unlike many other Mandarin wh-words that correspond to a single meaning (e.g., shei 'who', nali 'where'), zenme can be used to question either the manner or the cause of an event (Wang, 1943; Ding, 1961; Lü, 1980; Zhu, 1982; Peng, 1993; Shao, 1996; Tsai, 1999, 2000, 2007, 2008; Xiao, 2009). We refer to the two uses of zenme as manner zenme and causal zenme, respectively. For instance, when zenme occurs in serial verb constructions as in (1) or $\mathrm{PP}+\mathrm{VP}$ constructions as in (2), it is ambiguous between a causal reading and a manner reading (Peng, 1993; Shao, 1996). Interestingly, the ambiguity between manner zenme and causal zenme disappears in certain syntactic structures. For example, when zenme is preceded by verbal modifiers such as the temporal adverbial jingchang 'often' [see (3)], it receives the manner reading, whereas when it precedes these verbal modifiers, it obtains the causal reading, as in (4) (Peng, 1993; Shao, 1996; Tsai, 1999, 2000, 2007, 2008).

(1) Ni zenme bang ta xiu che? You how/why help he repair car 'How/Why do you help him repair the car?'
(2) Ni zenme gen ta jie qian?

You how/why from he borrow money

'How/Why do you borrow money from him?'

(3) Ni jingchang zenme bang ta xiu che? You often how helphe repair car 'How do you often help him repair the car?'

(4) Ni zenme jingchang bang ta xiu che? You why often help he repair car 'Why do you often help him repair the car?'

Causal zenme and manner zenme also exhibit asymmetries when they interact with modal verbs (Zhu, 1982; Peng, 1993; Shao, 1996; Tsai, 1999, 2000, 2007, 2008). Consider a typical modal verb hui 'will/would', for example. Hui 'will/would' expresses future tense or possibility. When zenme is structurally lower than hui, it indicates a manner; when zenme is structurally higher than hui, it denotes a cause (Shao, 1996; Tsai, 1999, 2000, 2007, 2008). Therefore, (5) questions the manner or instrument, by which you help him repair the car; by contrast, (6) questions the cause or reason, for which you help him repair the car.

(5) Ni hui zenme bang ta xiu che? You would how helphe repair car 'How would you help him repair the car?'

(6) Ni zenme hui bang ta xiu che? You why would helphe repair car 'Why would you help him repair the car?'

In the framework of the UG theory, Tsai (1999, 2000, 2007, 2008) attributed the distinct readings of zenme to their corresponding syntactic positions. Tsai's analysis is based on the cartographic approach by Rizzi $(1997,1999,2004)$ and Cinque (1999). According to Rizzi (1997), syntactic structures of clauses can be divided into three layers: the lexical layer, the inflectional layer and the complementizer layer. The lexical layer is headed by the verb and theta roles are assigned in this layer. The inflectional layer is headed by functional morphological specifications of the verb; case and agreement are licensed in this layer. The complementizer layer corresponds to the left periphery; topic, focus, interrogative and relative pronouns and some other functional categories are distributed in this layer, and thus this layer is often referred to as the split CP, as schematized in (7).

\section{(7) Force Top* Int Top* Focus Mod* Top* Fin IP}

Following this approach, Tsai (2008) argued that modal verbs relate to tense elements in the inflectional layer, and since causal zenme is hierarchically higher than modals, it is the sentential adverbial in the complementizer layer and merges directly into the left periphery. According to Tsai, causal zenme scopes over the entire IP and takes the corresponding event/state as its complement. The relatively lower manner zenme is a vP-modifier, which functions as the restrictive predicate of the underlying event argument associated with $\mathrm{vP}$ periphery, namely the lexical 
layer. Due to their syntactic positions, the interrogative scope of causal zenme is wider than modal verbs, and thus questions the causality of the event; whereas the interrogative scope of manner zenme is narrower than modals, so it questions the comitativity of the action, namely the manner and the way in which certain action is performed. The topography of Mandarin zenme adverbials is schematized in (8). More specifically, when zenme is structurally higher than the modal verb, it acts as the sentential outer adverbial, scoping over the entire IP and yielding a causal reading; when zenme locates between the modal verb and $\mathrm{vP}$, it functions as a vP-modifier, giving rise to a manner reading.

\section{(8) Force Top* Int Top* Focus Mod* Top* zenme $^{1} \quad \frac{z e n m e}{\text { Left periphery }}$ \\ Fin $\left[{ }_{T P}\right.$ Tense $\operatorname{Mod}^{*}\left[{ }_{v P}\right.$ modal $\quad \frac{\text { zenme }}{\text { vP periphery }}$}

(Tsai, 2008)

\section{Wh-ADJUNCTS IN CHILD LANGUAGE}

Previous theoretical work on zenme provides detailed descriptions and insightful analyses of the syntactic distributions and the corresponding semantic interpretations of zenme. However, to the best of our knowledge, only a few studies investigated children's acquisition of zenme in Mandarin. Prior research mainly used naturalistic data and reported that 4- and 5-year-old Mandarin-speaking children use zenme to ask both manner questions and causal questions (Li and Chen, 1997a,b; Kong and Chen, 1999). There is only one experimental study by Li et al. (2015) that directly examined Mandarin-speaking children's knowledge of the two interpretations of zenme. They found that in both comprehension (i.e., a picture identification task) and production (i.e., a question task), 4- to 6-year-old children showed no significant difference in response to the manner questions containing the "hui + zenme" sequence as opposed to the causal questions containing the "zenme + hui" sequence, but children performed slightly better with the latter. On the basis of the findings, they argued that Mandarin-speaking children have more difficulties in acquiring the manner questions than the causal questions. However, we wish to point out a few potentially serious problems with their study concerning test materials, results and data interpretation. First, the test materials in the picture identification task were strongly ambiguous. The test pictures that were supposed to be designed to match the causal reading actually depicted two concurrent events corresponding to the causal and manner reading, respectively. Depicting two events in one picture might have strengthened the visual salience of these pictures as compared to those that only described one event in the manner reading condition. This visual

\footnotetext{
${ }^{1}$ Tsai (2008) and Tang (2011) argued that when zenme precedes the subject NP such as in Zenme ni qu Beijing? 'How come you went to Beijing?' it expresses a strong exclamatory construal. When zenme is placed in this position (i.e., at ForceP), its illocutionary force changes from interrogation to exclamation or denial. But the denial zenme is not our concern in the present study. We only focus on the contrast between causal zenme and manner zenme.
}

salience might have significantly encouraged children to choose these pictures even when hearing the manner questions, because one of the events in these pictures corresponded to the manner reading anyway. This picture identification task, therefore, might have seriously underestimated children's comprehension of the manner questions. Regarding the production task, the task design did not meet the felicity condition to elicit causal zenme questions, in particular the counter-expectation prerequisite, namely, it is only felicitous to ask a causal zenme question when an on-going event contradicts the speaker's expectation, thereby leading the speaker to ask what has led to the unexpected event (Tsai, 2008). It has been well established that in order to test young children's linguistic knowledge, the test contexts must meet the felicity conditions on the use of the target structure, which otherwise might seriously undermine children's linguistic knowledge (Hamburger and Crain, 1982; Crain and Thornton, 1998; Gualmini, 2004, 2005; Gualmini et al., 2008). In addition, concerning the results and data interpretation, although there was slight difference in children's proportions of correct answers in response to the two types of questions, the difference did not reach statistical significance in both the comprehension and production task, and thus has no statistical meaning.

To examine children's acquisition of wh-adjuncts crosslinguistically, prior research found that English-speaking children seemed to exhibit asymmetrical patterns in the acquisition of how and why questions. It has been reported that English-speaking children acquired why questions later than how questions, and in fact among all wh-phrases why is the last to show full mastery of subject-auxiliary inversion (de Villiers, 1991; Rowland and Pine, 2000; Rowland et al., 2005; Thornton, 2008). The late acquisition of why questions led some researchers to propose that English-speaking children initially have different structural representations of questions from adults (de Villiers, 1991; Thornton, 2008). For instance, de Villiers (1991) proposed that English-speaking children do not initially project a $\mathrm{CP}$ phrase, and thus instead of moving a wh-phrase to [Spec, CP], which triggers subject-auxiliary inversion, they simply adjoin the wh-phrase to [Spec, IP], which does not trigger the inversion. According to de Villiers (1991), the linguistic input that triggers children to reanalyze the position of $w h$-phrases as in [Spec, $\mathrm{CP}]$ position is the embedded questions with a $w h$-phrase that has been moved from the original position to the intermediate [Spec, CP] position, as in the example John wondered what Bill ate last night. It has been argued that why lags behind how and other wh-words in children's reanalysis process, which, according to de Villiers (1991), was presumably due to the fact that the triggering evidence of embedded why questions is limited in parental input. However, as de Villiers (1991) also pointed out, input alone is not sufficient to account for children's errors of subject-auxiliary inversion, but rather the fundamental source of children's non-adult why questions is their non-adult structural representations.

To take stock, it is interesting and important to study this how/why asymmetry from a cross-linguistic perspective in order to identify language universal and language-specific patterns underlying children's acquisition of wh-adjuncts. However, on the basis of such limited prior research on Mandarin, it is 
difficult to draw any conclusive generalizations about Mandarinspeaking children's acquisition of the two readings of zenme, in particular the contrast between causal zenme and manner zenme in complex structures containing modal verbs. To address these unresolved issues, the present paper reports two experimental studies that aimed to investigate Mandarin-speaking children's understanding of the two readings of zenme, and in particular, we were interested to see whether young children can make use of the structural relation between zenme and modal verbs to distinguish between the two readings. As discussed, there are two major competing approaches to child language acquisition: the UGbased approach and the usage-based approach. What is crucial for the present paper is that the two approaches make different predictions about Mandarin-speaking children's acquisition of the two readings of zenme, in particular in structures that involve hierarchical relations between zenme and the modal verb hui. Therefore, the present findings can, to some extent, inform us about the debate between the two approaches. The usage-based approach would predict that the acquisition of the two readings of zenme does not involve hierarchical structures. Rather, the two uses of zenme would be treated as separate constructions associated with separate functions, and the acquisition of the two uses of zenme depends heavily on the linguistic input children are being exposed to. Thus, on this account the more frequent use of zenme in the linguistic input should be acquired earlier than the less frequent one, and children do not rely on hierarchical structures to understand the two readings of zenme. By contrast, on the UG-based account children are expected to acquire the two uses of zenme by mastering the mapping relations between its syntactic positions and the corresponding semantic interpretations. More specifically, following Tsai's (2008) analysis with the UG framework, the manner reading is related to VP in the lexical layer of the structure, whereas the causal reading involves $\mathrm{CP}$, namely the left periphery, of the structure. Therefore, to correctly derive the causal and manner readings of zenme, children need, first, to get the syntactic positions of zenme right, and then to map the syntactic positions onto the corresponding semantic interpretations. According to the UG-based approach, children rely on hierarchical structures to acquire the two uses of zenme and they might exhibit asymmetries in the acquisition of the two uses of zenme, due to their non-adult structural representations of zenme. This prediction is based on previous research that observed an asymmetry in the acquisition of higher syntactic structures related to the $\mathrm{CP}$ layer versus the acquisition of lower syntactic structures relevant to the IP and VP layers. For example, Platzack (2001) reported that Swedishspeaking and German-speaking young children produced the syntax of lower structural levels (the IP and VP layers) in an adult-like manner, but they have problems producing the syntax of the higher structural level (the CP layer). Findings in support of children's difficulty with the syntax of the CP layer at the left periphery have also been observed in Catalanspeaking, English-speaking, French-speaking, Greek-speaking and Spanish-speaking children (Rizzi, 1994; Müller et al., 1996; Radford, 1996; Grinstead, 1998; Marinis, 2004; Spinner and Grinstead, 2006). For instance, Spinner and Grinstead (2006) found that German-speaking children acquired constructions that involve the $\mathrm{CP}$ layer (i.e., fronted-object constructions and wh-questions) significantly later than those that do not involve the CP layer. Spinner and Grinstead (2006) dubbed this as the Left Peripheral Delay. According to this proposal, children acquire constructions that involve the CP layer of the left periphery relatively late, because the CP layer is proposed to be relevant to discourse functions, like topic/focus and interrogatives (Rizzi, 1997; Poletto, 2000; Benica' and Poletto, 2004), and the integration of discourse/pragmatics functions into syntax/semantics takes time to develop. In other words, the mapping between syntax/semantics and discourse/pragmatics is not well established until at a relatively late stage of language development. Young children do not quite have an adultlike representation of the $\mathrm{CP}$ layer that is associated with discourse functions.

Note that in the current study the derivation of the two types of zenme questions involves different structural layers, the causal zenme question involves the $\mathrm{CP}$ layer and the manner zenme question relates to the VP layer. We were interested to find out whether Mandarin-speaking children also exhibited a similar asymmetry as observed in other languages. In the following sections, we first present two experimental studies that investigated Mandarin-speaking children's understanding of the two types of zenme questions, and then we discuss which approach better explains the experimental findings.

\section{EXPERIMENT 1}

Experiment 1 was designed to see whether Mandarin-speaking children interpret zenme ambiguously between a causal reading and a manner reading, and whether they exhibit a preference for one reading over the other. As discussed, both the causal reading and the manner reading are allowed when zenme occurs in serial verb constructions [see (1)] and PP + VP constructions [see (2)]. We were interested to find out how children interpret zenme in these two structures when both readings are made available in the context.

\section{Participants}

Forty monolingual Mandarin-speaking children participated in Experiment 1: twenty 4-year-olds (11 boys and 9 girls, age range $4 ; 0-4 ; 11$, mean 4;6), and twenty 5 -year-olds ( 13 boys and 7 girls, age range $5 ; 0-5 ; 9$, mean $5 ; 4)$. The child participants were recruited from Beijing Taolifangyuan Kindergarten and had no reported history of speech, hearing or language disorders. In addition, 18 Mandarin-speaking adults (age range 18-31, mean 25) were tested as controls. They were students at Tsinghua University, and had no self-reported speech or hearing disorders.

\section{Materials and Design}

We used a Question-Answer task, an extension of the Truth Value Judgment Task by Crain and Thornton (1998). Four test stories were constructed. For each story, one test sentence and one filler sentence were created. So there were four test sentences and four filler sentences in total. See Appendix A for all the test and filler sentences. Two of the test sentences used PP + VP 
constructions [see (9)] and two used serial verb constructions [see (10)]. As discussed, in both constructions zenme is ambiguous between a causal reading and a manner reading.

(9) Xiaoyu zenme ti qingwa cang baoxiang? Fish how/why for frog hide treasure box a. Manner reading: How did the fish hide the treasure box for the frog?

b. Causal reading: Why did the fish hide the treasure box for the frog?

(10) Hema zenme dai xiaogou hui jia? Hippo how/why take dog return home a. Manner reading: How did the hippo take the dog home? b. Causal reading: Why did the hippo take the dog home?

The test sentences were produced by a female native speaker of Beijing Mandarin. Note that prosodic cues (i.e., pitch accent) can be used to distinguish causal zenme from manner zenme. Specifically, when zenme is accented, the sentence expresses a manner question; by contrast, if other elements instead of zenme is accented, the sentence asks a causal question (Zhu, 1982; Peng, 1993; Shao, 1996). Thus, in order to control for potential prosodic effects on children's interpretation of zenme questions, the speaker was asked to produce the test sentences using the same intonation pattern (i.e., level intonation) and with no words being accented. A post-recording survey was conducted to make sure that the test sentences were produced successfully. Eighteen Mandarinspeaking adults participated in this survey, where they were presented with each recorded sentence and were asked to judge whether the sentence has level intonation and if any particular word was accented in the sentence. The findings were that all the test sentences were judged to be in level intonation, and no words in any of the test sentences were judged to be accented.

A typical trial is used to illustrate the test scenario. On this trial, the experimenter acted out a story about a fish and a frog in Mandarin. The English translation of the story is given as follows.

This is a story about a fish and a frog. They live in the same village, but the fish does not like the frog, because the frog always comes to bully the fish. The fish decides never to talk to the frog. One day the frog finds a treasure box and he wants to hide it. But the frog cannot lift the treasure box, because it is too heavy. At this time, the fish passes by. The frog walks to the fish and asks him to help hide the treasure box. At first, the fish does not want to help the frog, because he does not like the frog. Then the frog comes up with an idea. He knows that the fish likes gold coins. So he takes out a gold coin and says to the fish "Could you help me hide the treasure box? I can give you a gold coin." The fish loves gold coins and cannot resist the temptation of getting a gold coin, so he changes his mind and decides to offer his help (Note that the causal reading is fulfilled at the point, see Figure 1). The frog and the fish lift the treasure box together and they start to look for a place to hide the treasure box. The frog asks the fish where they should hide it. The fish suggests that they hide it into his shell. The fish then opens his shell and puts the treasure box into

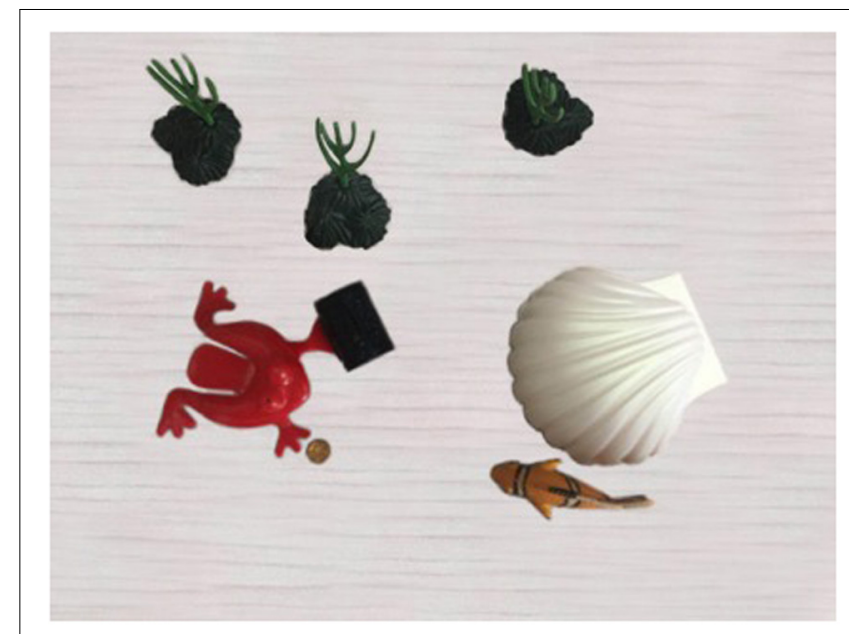

FIGURE 1 | The story scene corresponding to the causal reading.

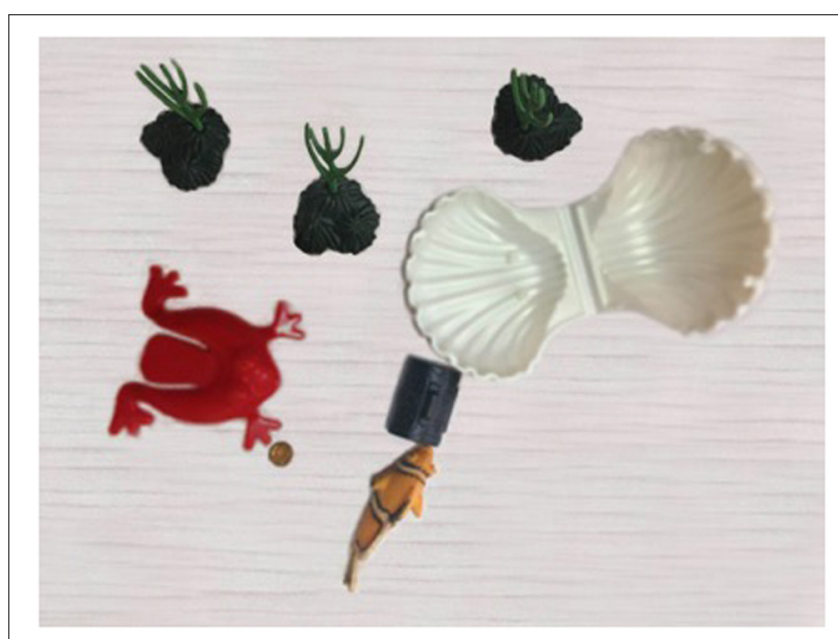

FIGURE 2 | The story scene corresponding to the manner reading.

it (Note that the manner reading is established at this point, see Figure 2). The frog gives the fish a gold coin as promised.

Figure 1 illustrates the scene corresponding to the causal reading of zenme. Figure 2 displays the scene corresponding to the manner reading of zenme.

We wish to highlight three design features. First, as discussed earlier, in order to test young children's linguistic knowledge, the test contexts must meet the felicity conditions on the use of the target structure, which otherwise might seriously undermine children's linguistic knowledge (Hamburger and Crain, 1982; Crain and Thornton, 1998; Gualmini, 2004, 2005; Gualmini et al., 2008). It is generally acknowledged that it is pragmatically appropriate to ask a manner zenme question when a potential tool or method (aka the comitativity of the action) is explicitly detectable in the context; and it is felicitous to raise a causal zenme question when an on-going event contradicts the speaker's expectation (aka the counter-expectation prerequisite), thereby leading the speaker to ask what has led to the unexpected event 
(Tsai, 2008). So, to satisfy the felicity conditions of the two uses of zenme, the comitativity of the action and the counter-expectation prerequisite were clearly established in the stories. In the example story, to satisfy the felicity condition on the use of the causal question 'why did the fish hide the treasure box for the frog?', a counter-expectation was established when the fish finally agreed to help the frog despite the fact that he was often bullied by the frog. Meanwhile, the fish indicated that his shell was an ideal tool to perform the hiding action, so as to satisfy the felicity condition on the use of the manner question 'how did the fish hide the treasure box for the frog?' The second design feature is that we made available both the causal reading and the manner reading in each story. Third, to control for potential salience effects on participants' interpretations due to the order of mention, the sequence of events that corresponded to the two readings was counterbalanced across the four stories. In two of the stories, the causal reading was established first and in the other two, the manner reading was realized first. In the example story, the causal reading was established before the manner reading.

The test sentence that was constructed for this example story was the one in (9). The filler sentence corresponding to this story was given in (11), which is a simple wh-question containing shenme 'what.'

\section{(11) Baoxiang limian you shenme? Treasure box inside have what 'What is inside the treasure box?'}

On the example trial, when the puppet produced the test sentence in (9), the participants were instructed to help the puppet answer the question. The participants heard four test sentences containing zenme, as in (9) and (10), and four filler sentences containing shenme, as in (11). On two of the trials, the participants were presented with the test sentence first, followed by the filler sentence. On the other two trials, the participants heard the filler sentence first.

\section{Procedure}

In this Question-Answer task, before the test session, the children were given one warm-up session, in which a puppet who appeared on a laptop computer screen asked simple questions about story settings (see Appendix B). This warm-up session was used to familiarize the participants with the task. Only those children who correctly answered all the questions in this session were included in the test session. In addition, children who were too shy to interact with the puppet were not invited to the test session. In Experiment 1, all the child participants correctly answered the warm-up questions and then proceeded to the test session. In the test session, the experimenter acted out stories in front of the child participant using toy props, and the puppet watched the stories alongside the child participant. In the story, the puppet would ask the child a question using a test sentence, and the child was instructed to answer the question. The test sentences were prerecorded and were presented to the participant through the laptop computer connected to an external speaker to make it appear that the puppet was talking. It was made clear to the participants that the puppet did not always pay close attention to the story and thus sometimes he might get confused about what happened in the story. When he was unsure about what happened in the story, he would ask a question. On each trial, the participants' task was to help the puppet better understand the story by answering the questions for the puppet.

The participants were introduced to the task individually and then tested individually in a quiet room in the Kindergarten. The adult participants were tested using a videotaped version of the same task. They heard the same stories as presented to the child participants. At the end of each story, they were also instructed to answer the questions.

\section{Predictions}

If participants interpreted zenme questions as manner questions, then in response to the puppet's question in (9), they would be expected to provide an answer "He hid the treasure box into his shell." If, on the other hand, participants interpreted zenme questions as causal questions, then they should answer "Because the frog gave him a gold coin" in response to the same question.

\section{Data Treatment}

We coded the responses as manner reading when the participant answered the question by indicating a manner (e.g., Xiaoyu ba baoxiang cang zai beike $l i$ 'The fish hid the treasure box into the shell', or Ta dakai beike fang jinqu 'He opened the shell and put it in'), and those as causal reading when participants answered the question by indicating a cause (e.g., Yinwei qingwa gei ta yige jinbi, 'Because the frog gave him a gold coin' or Yinwei xiaoyu hen xihuan jinbi 'Because the fish liked the gold coin very much'). Other irrelevant responses or failure to provide any responses were coded as "others."

We wish to note that we did not ask children to limit their answers to a certain number of sentences or to a certain length, yet they responded to both the manner and causal questions mainly using a simple sentence as indicated in the example responses. Children's responses of both types are generally equal in length and in structural complexity. Thus, it seems quite unlikely that children's preference for the manner reading was due to that manner responses were often associated with longer answers and thus were easier to be produced by children ${ }^{2}$.

\section{Results and Discussion}

All the participants responded correctly to the filler questions $100 \%$ of the time. So, their data were all included in the final analyses.

For each participant, we first calculated the number of responses indicating a manner reading and the number of responses corresponding to a causal reading. We then computed the proportions of the two types of responses (i.e., the two readings). Figure 3 shows the mean proportions of the two

${ }^{2}$ This section responds to a concern raised by one of the reviewers about whether children's responses indicating a manner reading were longer than those indicating a causal reading, showing that children's preference for the manner reading was presumably due to that manner responses were often associated with longer answers and thus were easier to be produced by children. We appreciate the opportunity to clarify the point, and have now made clear that children's responses of both types are generally equal in length and in structural complexity. 


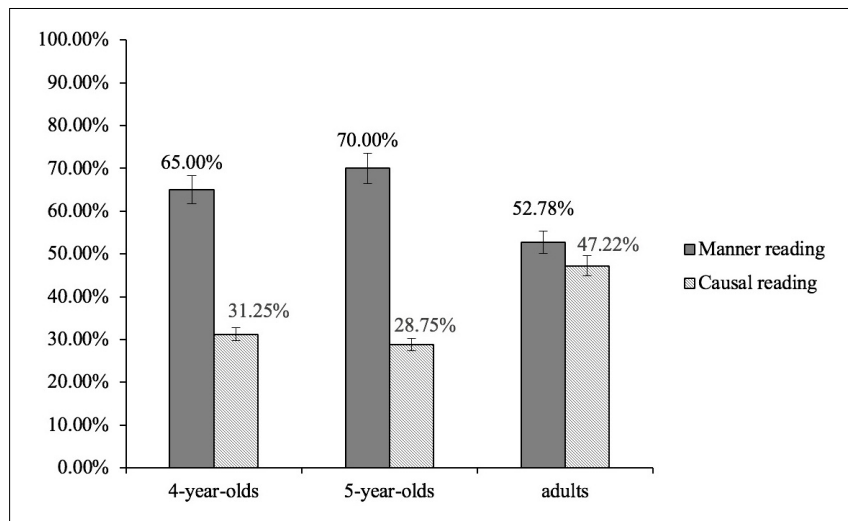

FIGURE 3 | Mean proportions of the two readings by the three age groups. Error bars indicate SEs.

readings by the three age groups ${ }^{3}$. As indicated in Figure 3, all the three groups assigned two readings to zenme questions. The 4-year-olds assigned a manner reading to zenme questions $65.00 \%$ of the time, and the 5-year-olds and the adults did so $70.00 \%$ and $52.78 \%$ of the time, respectively. The 4 -year-olds assigned a causal reading to zenme questions $31.25 \%$ of the time, and the 5 -year-olds and the adults did so $28.75 \%$ and $47.22 \%$ of the time, respectively. The 4-year-olds and the 5-year-olds assigned more manner readings than causal readings to zenme questions, whereas the adults assigned the two readings equally often.

To assess the response patterns among the three groups statistically, generalized linear mixed models (GLMMs) were applied. We conducted the fitting process via functions lmer from package lme4 (v1.1-12) (Bates et al., 2015b) of the $\mathrm{R}$ (v3.2.5) software environment ( $\mathrm{R}$ Development Core Team, 2017). Satterthwaite approximation implemented in the package lmerTest (Kuznetsova et al., 2017) was used to estimate the degrees of freedom. The significance of predictors was determined using an alpha-level of 0.05 .

We treated the manner and the causal responses as two levels of the dependent variable when computing statistical models. In the full model, the fixed effects included the participants' group; the random effects included both items and participants, where both their intercepts and slopes were allowed to vary among all the fixed effects (Baayen et al., 2008; Barr et al., 2013). The full model's complexity was then reduced to see whether the reduced model could explain the same variance as the full model (Bates et al., 2015a). If it could, we would accept the simplified model.

The model results showed that for the two child groups, the proportion of the manner reading was significantly higher than that of the causal reading (the 4-year-olds: $\beta=1.10, S E=0.27$, $z=4.56, p<0.001$; the 5-year-olds: $\beta=1.22, S E=0.33, z=5.52$, $p<0.001)$. By contrast, for the adults, there was no significant difference between the proportion of the manner reading and that of the causal reading $(\beta=0.13, S E=0.23, z=0.51, p>0.05)$.

\footnotetext{
${ }^{3}$ One 5 -year-old child and one 4-year-old child provided an uninterpretable answer in response to one of the four test sentences, respectively; one 4-year-old child provided irrelevant answers in response to two of the four test sentences. Thus, these four responses were not included in the final analyses.
}

The model results also revealed that age group (the adult group was treated as the baseline) was a reliable predictor for the participants' responses of both types. There was a significant difference in the proportion of manner readings between the 4year-olds and the adults $(\beta=1.05, S E=0.22, z=2.19, p<0.05)$, and between the 5 -year-olds and the adults $(\beta=1.07, S E=0.20$, $z=2.24, p<0.05)$. In addition, there was a significant difference between the 4 -year-olds and the adults $(\beta=1.07, S E=0.18$, $z=2.61, p<0.01)$ and between the 5-year-olds and the adults $(\beta=1.13, S E=0.16, z=2.72, p<0.01)$.

The response patterns of three age groups, as shown in Figure 3, were supported by the statistical modeling. The findings are evidence that Mandarin-speaking children as young as 4 years of age access both manner and causal readings of zenme $e^{4}$ The ambiguity of zenme as discussed in the theoretical literature has been experimentally supported by data from both child and adult Mandarin.

However, it is also worth pointing out that the 4-year-olds and the 5-year-olds assigned the manner reading to zenme significantly more often than they did with the causal reading, but the adults assigned the two readings equally often. The findings suggest that unlike adults, Mandarin-speaking children prefer the manner reading over the causal reading even though both readings are available to them.

\section{EXPERIMENT 2}

Experiment 2 was designed to investigate whether young Mandarin-speaking children are able to use the syntactic positions of zenme relative to modal verbs to disambiguate the two readings of zenme, and whether children exhibit a developmental trajectory when acquiring the mapping relations between the syntactic positions of zenme and its corresponding semantic interpretations.

As discussed, the syntactic positions of zenme as relative to modal verbs can be used to disambiguate between the causal reading and the manner reading. For example, when zenme is structurally lower than the modal verb hui 'will/would,' as in (12a), it yields a manner reading; but when zenme is structurally higher than the modal verb hui, as in (13a), it gives rise to a causal reading. Experiment 2 used minimal pairs as in (12a) and (13a).

(12) a. Xiaoyu hui zenme ti qingwa cang baoxiang? Fish would how for frog hide treasure box 'How would the fish hide the treasure box for the frog?' b. Ta hui ba baoxiang cang zai beike li. He would BA treasure box hide in shell inside 'He would hide the treasure box into the shell.'

\footnotetext{
${ }^{4}$ One reviewer raised the concern that our results did not necessarily indicate that each child understands that zenme is ambiguous between a manner and a causal reading, because they each gave either a manner or a causal response to zenme. However, we wish to note that even the adults answered the zenme questions by choosing one reading over the other, but post-test interviews showed that they judged the zenme questions to be ambiguous $100 \%$ of the time. We could not ask children explicitly whether the zenme sentences were ambiguous, due to their immature metalinguistic ability, but the results clearly show that 4-year-olds as a group access both the manner and the causal reading of zenme.
} 
(13) a. Xiaoyu zenme hui ti qingwa cang baoxiang? Fish why would for frog hide treasure box 'Why would the fish hide the treasure box for the frog?'

b. Yinwei qingwa hui gei ta yi-ge jinbi. Because frog would give he one-CL gold coin 'Because the frog would give him a gold coin.'

\section{Participants}

One hundred and thirty monolingual Mandarin-speaking children participated in Experiment $2^{5}$. They were divided into three age groups. Forty children were between the age of 3;4 and $3 ; 11$ ( 22 boys and 18 girls, mean age $=3 ; 9$ ), 40 children were between $4 ; 1$ and 4;11 (23 boys and 17 girls, mean age $=4 ; 7$ ), and 50 children were between $5 ; 0$ and 5;11 (33 boys and 17 girls, mean age $=5 ; 6$ ). The child participants were recruited from Beijing Taolifangyuan Kindergarten and had no reported history of speech, hearing or language disorders. In addition, 40 Mandarin-speaking adults (age range 19-31, mean age $=23$ ) were tested as controls. They were students at Tsinghua University, and had no self-reported speech or hearing disorders. None of the participants had taken part in Experiment 1.

\section{Procedure}

We used a Question-Answer task. The experimental procedure in this experiment was identical to Experiment 1.

\section{Materials and Design}

The four stories used in Experiment 2 were identical to those used in Experiment 1. But Experiment 2 used different test structures. For each story, two types of test sentences were created, one containing zenme in a structurally lower position than the modal verb hui [see (12a)], and one with zenme in a structurally higher position than hui [see (13a)]. In addition to the two test sentences, one filler sentence was created for each story. The filler sentences were the same simple wh-questions containing shenme 'what' as in Experiment 1. See Appendix C for all the test and filler sentences.

We used a between-participants design. Half of the participants in each of the four age groups (i.e., twenty 3year-olds, twenty 4-year-olds, twenty five 5-year-olds and twenty adults) heard the sentence in (12a) and the other half heard the sentence in (13a). Across the trials, one group of participants heard four test sentences containing zenme in a structurally lower position than hui (Group A), and the other group were presented with four test sentences containing zenme in a structurally higher position than hui (Group B). In addition, both groups heard four filler sentences containing shenme 'what,' as in (11).

\section{Predictions}

If children can use the syntactic positions of zenme relative to modal verbs to distinguish the causal reading from the manner reading, then they should interpret sentences containing zenme

\footnotetext{
${ }^{5}$ In Experiment 2, two additional 3-year-olds who were unwilling to interact with the puppet in the warm-up session were not invited to the test session and thus were not included in the final sample.
}

in a structurally lower position than hui as manner questions, and they should interpret sentences containing zenme in a structurally higher position than hui as causal questions. On the example trial, in response to (12a), children would be expected to provide an answer in (12b) indicating the manner in which the fish would hide the treasure box (i.e., he would hide the treasure box into the shell); and in response to (13a), children should provide an answer in (13b) indicating the reason why the fish would hide the treasure box for the frog (i.e., because the frog would give him a gold coin).

\section{Results and Discussion}

We excluded data of one 3-year-old child in Group A from the final analyses, because he failed on two of the four filler questions. The rest of the participants responded correctly to at least three of the four filler questions, and thus were included in the analyses. For each participant we first coded their responses using the same criteria as in Experiment 1. We calculated the number of responses indicating a manner reading and the number of responses indicating a causal reading in response to the two structures. We then computed the proportion of the two types of readings in each condition. Figure 4 summarized the results. As indicated in the solid bars in Figure 4, when responding to sentences containing zenme in a structurally lower position than $h u i$, as in (12a), all the age groups consistently provided correct manner interpretations. The adults provided answers indicating a manner interpretation $96.25 \%$ of the time, the 3 -year-olds, 4-year-olds, and the 5 -year-old did so $85.53 \%$, $83.75 \%$, and $94.00 \%$ of the time, respectively. When responding to sentences containing zenme in a structurally higher position than hui, as in (13a), different response patterns were observed among the four age groups. The adults and the 5-year-olds consistently provided correct causal interpretations $95.00 \%$ and $89.00 \%$ of the time, respectively. The 4 -year-olds provided causal interpretations $75.00 \%$ of the time. But the 3-year-olds provided causal interpretations only $36.25 \%$ of the time, and $49.00 \%$ of the time they provided answers indicating a manner interpretation.

Again, generalized linear mixed models were applied to assess the response patterns among the four age groups. We used the same fitting process as in Experiment 1. The best-fitting model treated age group (i.e., four age groups) and sentence type (two types of structures) as fixed effects, with random intercepts and slopes for both participants and items.

The model results revealed the 5 -year-olds provided more causal interpretations than the 4-year-olds $(\beta=1.07, S E=0.21$, $z=2.51, p<0.01)$ and the 3 -year-olds $(\beta=1.09, S E=0.24$, $z=4.49, p<0.001)$; and the 4 -year-olds provided more causal interpretations than the 3 -year-olds $(\beta=1.11, S E=0.19, z=2.50$, $p<0.01)$.

The model results also showed that in response to sentences containing zenme in a structurally lower position than hui (manner questions), no significant effect of age group (the adult group was treated as the baseline) was observed among the four age groups in the proportion of their manner readings (3-yearolds versus adults: $\beta=0.09, S E=0.13, z=1.03, p>0.05$; 4-year-olds versus adults: $\beta=0.08, S E=0.17, z=0.67, p>0.05$; 5-year-olds versus adults: $(\beta=0.08, S E=0.19, z=0.59, p>0.05)$. 


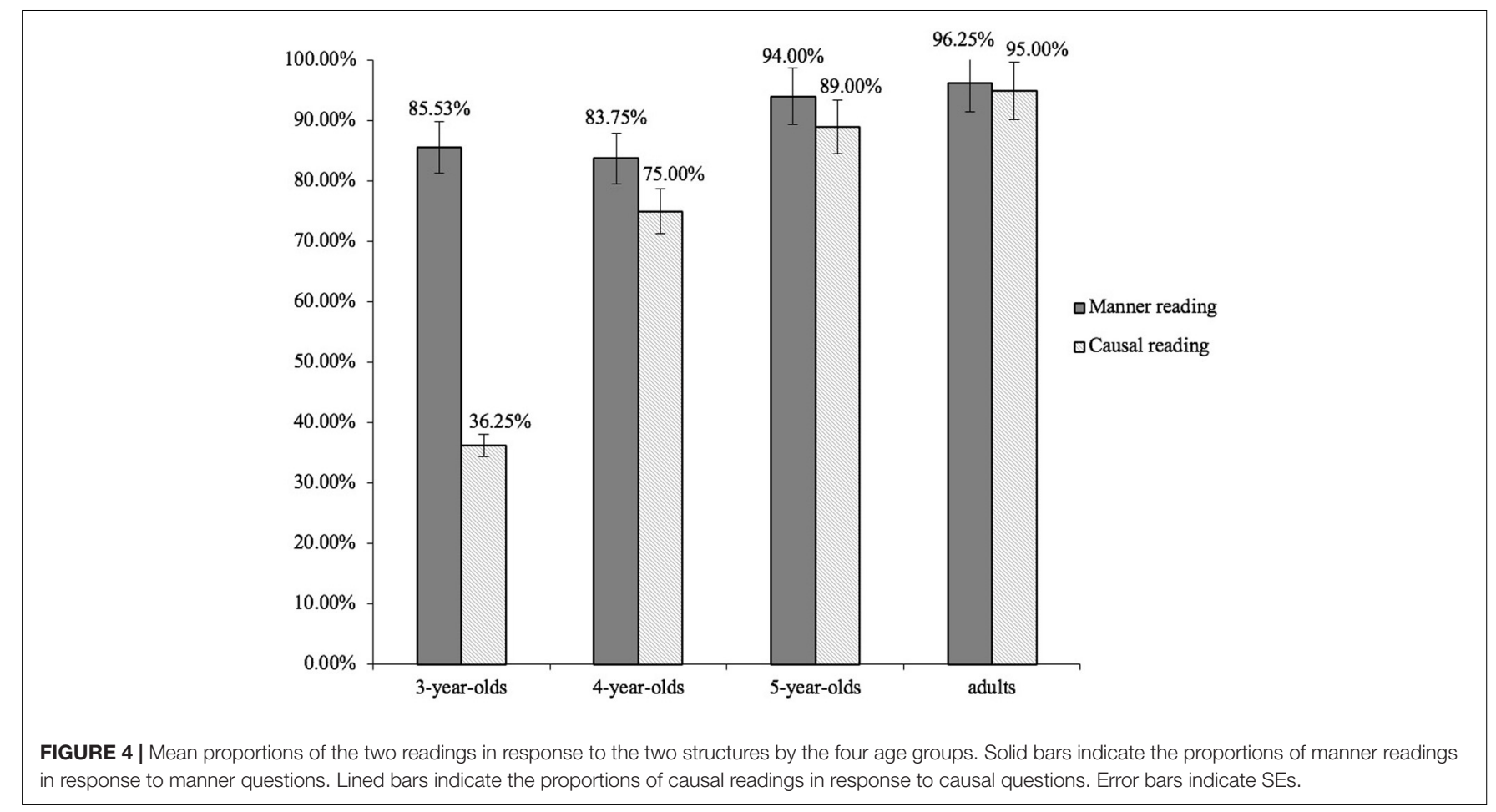

By contrast, in response to sentences containing zenme in a structurally higher position than hui (causal questions), age group was a reliable predictor of their responses. More causal interpretations were observed in the adults than in the 4-yearolds $(\beta=1.16, S E=0.25, z=2.77, p<0.01)$ and the 3 -year-olds $(\beta=1.19, S E=0.24, z=4.87, p<0.001)$, but no significant difference was found between the adults and the 5-year-olds $(\beta=0.11, \mathrm{SE}=0.17, z=0.70, p>0.05)$.

The findings suggest that the 5-year-old Mandarin-speaking children, like the adults, are able to use the structural relations between zenme and modal verbs to disambiguate the two readings of zenme. The 3-year-olds, however, are still in the stage of working out how the syntactic positions of zenme are mapped onto the relevant semantic interpretations. When presented with structures where zenme is structurally higher than hui, the 3-yearolds tend to interpret them in the same way as structures where zenme is structurally lower than hui. The 4-year-olds are in a transitional stage and they are generally able to map the syntactic positions onto the corresponding semantic interpretations of zenme, although they are not quite as good as the 5-year-olds. In general, children exhibit a developmental trajectory when acquiring the mapping relations between the syntactic positions of zenme and its corresponding semantic interpretations. The critical change occurs at around 4 years of age.

\section{CORPUS ANALYSIS}

To investigate whether parental input had an impact on children's preference for the manner reading over the causal reading, we analyzed the parental input in the CHILDES Database (MacWhinney, 2000). More specifically, we were interested to see if the manner reading is a more frequent use of zenme than the causal reading by caretakers, i.e., whether there is sufficient parental input for the manner reading of zenme but not for the causal reading of zenme.

We did a corpus survey of 62,309 adult utterances of 10 children in the Beijing Corpus ${ }^{6}$ in the CHILDES Database (Tardif, 1993, 1996). Table 1 reports the token frequencies of the causal

${ }^{6}$ The Beijing Corpus contains files of conversations between adults and individual child participants between the ages of 1;9.3 and 2;2.7. The computerized language analysis program (CLAN) was used to determine the number of utterances and the number of target words, as well as to identify the immediate context of the target words.

TABLE 1 | Token frequencies of causal zenme and manner zenme in bare forms and in constructions containing the modal verb hui in Beijing Corpus (Tardif, 1993, 1996).

\begin{tabular}{lcccc}
\hline Children & Causal zenme & Manner zenme & zenme $>$ hui & hui $>$ zenme \\
\hline BB & 53 & 54 & 2 & 0 \\
CX & 26 & 13 & 1 & 0 \\
HY & 17 & 25 & 0 & 0 \\
LC & 27 & 18 & 0 & 0 \\
LL & 39 & 26 & 1 & 0 \\
LXB & 48 & 34 & 1 & 0 \\
TT & 21 & 23 & 0 & 0 \\
WW & 26 & 29 & 0 & 0 \\
WX & 48 & 68 & 0 & 0 \\
YY & 51 & 54 & 0 & 0 \\
Total & $\mathbf{3 5 6}$ & $\mathbf{3 4 4}$ & $\mathbf{5}$ & $\mathbf{0}$
\end{tabular}

The bold values indicate the total numbers of token frequencies of causal zenme and manner zenme in bare forms and in constructions containing the modal verb hui in Beijing Corpus, respectively. 
zenme and the manner zenme in bare forms and in constructions containing the modal verb hui for each child. As illustrated in Table 1, both the tokens of the manner zenme and the causal zenme in bare forms are limited in number. For these ten children, there was no significant difference in the adult input between the token frequencies of the manner zenme and the causal zenme in bare forms $(z=0.26, p>0.05)$. In addition, we found that the manner zenme constructions (with zenme in a structurally lower position than the modal verb hui) and the causal zenme constructions (with zenme in a structurally higher position than the modal verb hui) are even scarcer, with only five instances of causal zenme constructions (e.g., Zenme hui teng $a$ ? 'Why would it hurt?'), and not a single instance of manner zenme constructions. Again, for these ten children, no significant difference was observed between the token frequencies of the manner zenme constructions and the causal zenme constructions $(z=1.89, p>0.05)$.

\section{GENERAL DISCUSSION}

The present paper sought to investigate children's acquisition of zenme in Mandarin. Two experiments were conducted. Experiment 1 was designed to see whether young Mandarinspeaking children understand that the wh-adjunct zenme is ambiguous between a causal reading and a manner reading. Experiment 2 examined whether young children are able to use the syntactic positions of zenme relative to modal verbs to disambiguate the two readings of zenme and whether children exhibit a developmental trajectory when acquiring the mapping relations between the syntactic positions of zenme and its corresponding semantic interpretations.

The findings of Experiment 1 show that Mandarin-speaking children as young as 4 years of age access both the manner and the causal readings of zenme, but they prefer the manner reading over the causal reading. The findings of Experiment 2 demonstrated that children exhibit a developmental trajectory when acquiring the mapping relations between the syntactic positions of zenme and its corresponding semantic interpretations. 5-yearold children are able to use the structural relations between zenme and modal verbs to disambiguate the two readings of zenme; 3-year-olds, however, are still in the stage of working out how the syntactic positions of zenme are mapped onto the relevant semantic interpretations. When presented with structures where zenme is structurally higher than hui, 3-yearolds tend to interpret them in the same way as structures where zenme is structurally lower than hui. The findings suggest that young Mandarin-speaking children have a preference for the manner reading over the causal reading. The manner reading seems to be the default reading of zenme.

At this point, an interesting question to ask would be why the manner reading is the default reading for young children. This is also the point to discuss how the data can inform us about the debate between the two competing approaches of child language acquisition, i.e., which approach can better explain the experimental findings.
On the usage-based account, the more frequent use of zenme in the linguistic input should be acquired earlier than the less frequent one. In other words, children acquire the manner use of zenme earlier than the causal use of zenme, because they are exposed to more manner uses than causal uses of zenme in the input. However, the findings of the corpus analysis showed that there was no significant difference between the token frequencies of the manner zenme constructions and the causal zenme constructions. The discrepancy between the adult input and the children's interpretation of zenme in the two experiments provides evidence that input alone cannot explain Mandarin-speaking children's acquisition of the two readings of zenme.

In contrast, on the UG-based approach, children acquire the manner zenme question earlier than the causal zenme question, because the causal zenme question involves the CP layer and the manner zenme question relates to the VP layer. The CP layer at the left periphery of the structure is often associated with discourse functions, and the mapping between syntax/semantics and discourse/pragmatics is not well established until at a relatively late stage of language acquisition (Rizzi, 1994; Müller et al., 1996; Radford, 1996; Grinstead, 1998; Platzack, 2001; Marinis, 2004; Spinner and Grinstead, 2006). On this account, children's preference for the manner reading over the causal reading can be easily explained. Children's initial tendency to analyze zenme as manner zenme rather than causal zenme, is presumably due to their ability to represent the VP layer (corresponding to the manner zenme) but their non-adult representation of the $\mathrm{CP}$ layer (corresponding to the causal zenme). Overall, two features of the UG-based approach make it a more suitable account for young Mandarin-speaking children's acquisition of the two readings of zenme. One is the acknowledgment of the discrepancy between the linguistic knowledge acquired by young children and the linguistic input they have been exposed to, and the second is the emphasis of the importance of hierarchical structure in children's acquisition of linguistic knowledge.

Before concluding, we wish to point out that in addition to structural reasons, the manner reading default might also have to with some lexical factors. In Mandarin, there is another wh-word weishenme 'why', which is often used to question the cause of an event. It is possible that young children initially use weishenme 'why' to inquire about reasons and zenme 'how' to inquire about manners. There might be a division of labor between zenme and weishenme in the early lexicon.

We also wish to point out that our corpus analysis was based on the parental input in the Beijing Corpus in the CHILDES Database, which might be limited in scope and content. Although it is the standard practice to analyze the parental input in the CHILDES Database when discussing the role of input in child language acquisition (Crain et al., 2017; Yang et al., 2017; Koring et al., 2020), we acknowledge that to gain a comprehensive understanding of the role of input, further research is required to investigate children's other sources of input including their story books, textbooks, cartoons and interactions with teachers at kindergartens and at early childhood education centers. 
To summarize, our experimental findings provide empirical evidence for the ambiguity of the wh-adjunct zenme discussed in the theoretical linguistics literature. Young children as adults access both the manner and the causal readings of zenme, although they exhibit a strong preference for the manner reading. The present paper provides a good example of convergence of child language acquisition and theories of linguistic structures. Although children initially assign a manner reading to zenme, by age 4 or 5 they become able to use syntactic cues, i.e., the syntactic positions of zenme relative to modal verbs, to arrive at the correct interpretation of zenme. In addition, the findings, to some extent, can inform us about the debate of the two competing approaches to child language acquisition: the UG-based approach and the usagebased approach. In the current study, the patterns exhibited by young children in their acquisition of zenme questions can be better explained by the UG-based approach than the usagebased approach.

\section{DATA AVAILABILITY STATEMENT}

The data that support the findings of this study are available from the corresponding author upon request.

\section{REFERENCES}

Ambridge, B., and Lieven, E. V. (2011). Child Language Acquisition: Contrasting Theoretical Approaches. Cambridge: Cambridge University Press.

Baayen, R. H., Davidson, D. J., and Bates, D. M. (2008). Mixed-effects modeling with crossed random effects for subjects and items. J. Mem. Lang. 59, 390-412. doi: 10.1016/j.jml.2007.12.005

Barr, D. J., Levy, R., Scheepers, C., and Tily, H. J. (2013). Random effects structure for confirmatory hypothesis testing: keep it maximal. J. Mem. Lang. 68, 255278. doi: 10.1016/j.jml.2012.11.001

Bates, D. M., Kliegl, R., Vasishth, S., and Baayen, R. H. (2015a). Parsimonious mixed models. arXiv [Preprint]. arXiv: 1506.04967.

Bates, D. M., Mächler, M., and Bolker, B. and Walker, S. (2015b). Fitting linear mixed-effects models using lme4. J. Stat. Softw. 67, 1-48. doi: 10.18637/jss.v067. i01

Benica, P., and Poletto, C. (2004). "Topic, focus, and V2. Defining the CP sublayers," in The Structure of CP and IP. The Cartography of Syntactic Structures, Vol. 2, ed. L. Rizzi (New York: Oxford University Press), 52-75.

Bybee, J. (2001). Phonology and Language use. Cambridge: Cambridge University Press.

Chomsky, N. (1965). Aspects of the Theory of Syntax. Cambridge, MA: MIT Press.

Chomsky, N. (1975). Reflections on Language. New York: Pantheon.

Chomsky, N. (1980). Rules and Representations. New York: Columbia University Press.

Cinque, G. (1999). Adverbs and Functional Heads: A Cross-Linguistic Perspective. New York, NY: Oxford University Press.

Crain, S., Koring, L., and Thornton, R. (2017). Language acquisition from a biolinguistic perspective. Neurosci. Biobehav. Rev. 81, 120-149. doi: 10.1016/j. neubiorev.2016.09.004

Crain, S., and Nakayama, M. (1987). Structure dependence in grammar formation. Language 63, 522-543. doi: 10.2307/415004

Crain, S., and Pietroski, P. (2001). Nature, nurture and universal grammar. Linguist. Philos. 24, 139-186. doi: 10.1023/A:10056941 00138

Crain, S., and Thornton, R. (1998). Investigations in Universal Grammar: A Guide to Research on the Acquisition of Syntax and Semantics. Cambridge, MA: MIT Press.

\section{ETHICS STATEMENT}

The study was approved by the Ethics Committee of the School of Medicine, Tsinghua University, 20170018. Written informed consent has been obtained from each child participant's parents and each adult participant.

\section{AUTHOR CONTRIBUTIONS}

$\mathrm{JL}$ and PZ contributed equally to this work.

\section{FUNDING}

This work was supported by the National Social Science Foundation of China (16BYY076) to PZ.

\section{ACKNOWLEDGMENTS}

The authors would like to thank the children, the parents, and the teachers at the Taolifangyuan Kindergarten, Beijing, China, for their assistance and support in running the study.

de Villiers, J. (1991). "Why questions?," in UMOP Special Edition: Papers in the Acquisition of Wh, eds T. Maxfield and B. Plunkett (Amherst, MA: GLSA), 155-175.

Ding, S. (1961). Xiandai Hanyu Yufa Jianghua (Discussions on Modern Chinese Grammar) (in Chinese). Beijing: The Commercial Press.

Goldberg, A. (2003). Constructions: a new theoretical approach to language. Trends Cogn. Sci. 7, 219-224. doi: 10.1016/S1364-6613(03) 00080-9

Goldberg, A. (2006). Constructions at Work: The Nature of Generalizations in Language. New York: Oxford University Press.

Grinstead, J. (1998). Subject, Sentential Negation and Imperatives in Child Spanish and Catalan. Doctoral dissertation, University of California, Los Angeles, CA.

Gualmini, A. (2004). Some knowledge children don't lack. Linguistics 42, 957-982.

Gualmini, A. (2005). Some facts about quantification and negation one simply cannot deny: a reply to Gennari and MacDonald. Lang. Acquis. 13, 363-370. doi: 10.1207/s15327817la1304_5

Gualmini, A., Hulsey, S., Hacquard, V., and Fox, D. (2008). The question-answer requirement for scope assignment. Nat. Lang. Semantics. 16, 205-237.

Hamburger, H., and Crain, S. (1982). "Relative acquisition," in Language Development: Syntax and Semantics, Vol. 1, ed. S. A. Kuczaj (Hillsdale, NJ: Lawrence Erlbaum Associates), 245-274.

Kong, L., and Chen, C. (1999). Ertong yuyan zhong daici fazhan de shunxu ji qi lilun jieshi (The developmental sequence of pronouns in child language and theoretical accounts): (in Chinese). Appl. Linguist. 2, 41-46.

Koring, L., Giblin, I., Thornton, R., and Crain, S. (2020). Like dishwashing detergents, all analogies are not the same: a commentary on Ambridge (2020). First Lang. 1-4. doi: 10.1177/0142723720902292

Kuznetsova, A., Bruun Brockhoff, P. B, and Christensen, R. H. B. (2017). lmerTest package: Tests in linear mixed effects models. J. Stat. Softw. 82, 1-26. doi: 10.18637/jss.v082.i13

Li, C. R., Chen, C. D., and Yang, L. (2015). L1 acquisition of Chinese causal and manner questions: data from zenme hui and hui zenme. Concentric Stud. Linguist. 41, 1-35. doi: 10.6241/concentric.ling.41.2.01

Li, Y., and Chen, Q. (1997a). Ertong wenju lijie de qunan yu gean de bijiao yanjiu (Comparative study on children's interpretation of interrogative sentences based on multiple cases and individual cases) (in Chinese). Lang. Teach. Linguist. Stud. 4, 119-130. 
Li, Y., and Chen, Q. (1997b). Qunan ertong de wenju lijie (Study on children's interpretation of interrogative sentences based on multiple cases) (in Chinese). J. Huazhong Normal Univ. Hum. Soc. Sci. 36, 77-84.

Lieven, E. V. M., and Tomasello, M. (2008). "Children's first language acquisition from a usage-based perspective," in Handbook of Cognitive Linguistics and Second Language Acquisition, eds P. Robinson and N. C. Ellis (New York: Routledge), 168-196.

Lü, S. (1980). Xiandai Hanyu Babai ci (800 Words of Contemporary Chinese) (in Chinese). Beijing: The Commercial Press.

MacWhinney, B. (2000). The CHILDES Project: Tools for Analyzing Talk, 3rd Edn. Mahwah, NJ: Lawrence Erlbaum Associates.

Marinis, T. (2004). “Acquiring the left periphery of the modern Greek DP," in Studies in Natural Language and Linguistic Theory, Vol. 59, eds D. Adger, C. de Cat, and G. Tsoulas (Dordrecht: Kluwer), 359-382. doi: 10.1007/1-4020-1910$6 \_15$

Müller, N., Crysmann, B., and Kaiser, G. A. (1996). Interactions between the acquisition of French object drop and the development of the C-system. Lang. Acquis. 5, 35-63. doi: 10.1207/s15327817la0501_2

Peng, K. (1993). Shuo "zenme" (On zenme) (in Chinese). Lang. Teach. Linguist. Stud. 1, 114-125.

Platzack, C. (2001). The vulnerable C-domain. Brain Lang. 77, 364-377.

Poletto, C. (2000). The Higher Functional Field: Evidence from Northern Italian Dialects. New York: Oxford University Press.

Pullum, G., and Scholz, B. (2002). Empirical assessments of stimulus poverty arguments. Linguist. Rev. 19, 9-50. doi: 10.1515/tlir.19.1-2.9

R Development Core Team (2017). R: A Language and Environment for Statistical Computing. Vienna: R Foundation for Statistical Computing.

Radford, A. (1996). "Towards a structure-building model of acquisition," in Generative Perspectives on Language Acquisition, ed. H. Clahsen (Amsterdam: John Benjamins), 43-90.

Rizzi, L. (1994). Some Notes on linguistic theory and language development: the case of root infinitives. Lang. Acquis. 3, 371-393. doi: 10.1207/ s15327817la0304_2

Rizzi, L. (1997). “The fine structure of the left periphery," in Elements of Grammar, ed. L. Haegeman (Dordrecht: Kluwer), 281-338.

Rizzi, L. (1999). On the Position "int(errogative)" in the Left Periphery of the Clause. Siena: Ms. Università di Siena.

Rizzi, L. (2004). "Locality and the left periphery," in Structures and Beyond: The Cartography of Syntactic Structures, Vol. 3, ed. A. Belletti (New York, NY: Oxford University Press), 223-251.

Rowland, C. F., and Pine, J. M. (2000). Subject-auxiliary inversion errors and wh-question acquisition: 'what do children know?' J. Child Lang. 27, 157-181. doi: 10.1017/s0305000999004055

Rowland, C. F., Pine, J. M., Lieven, E. V., and Theakston, A. L. (2005). The incidence of error in young children's wh-questions. J. Speech Lang. Hear. Res. 48, 384-404. doi: 10.1044/1092-4388(2005/027)

Saxton, M. (2010). Child Language: Acquisition and Development. London: Sage Publications.

Shao, J. (1996). Xiandai Hanyu Yiwenju Yanjiu (Studies on Modern Chinese Interrogatives) (in Chinese). Shanghai: East China Normal University Press.
Spinner, P., and Grinstead, J. (2006). "Subjects, topicalizations and wh-questions in child German and Southern Romance," in Selected Proceedings of the 9th Hispanic Linguistics Symposium, eds N. Sagarra and A. J. Toribio (Somerville, MA: Cascadilla Press), 241-251.

Tang, S. W. (2011). On causal how in Chinese (in Chinese). Lang. Teach. Linguist. Stud. 2, 43-47.

Tardif, T. (1993). Adult-to-Child Speech and Language Acquisition in Mandarin Chinese. Doctoral dissertation, Yale University, New Haven, CT.

Tardif, T. (1996). Nouns are not always learned before verbs: evidence from mandarin speakers' early vocabularies. Dev. Psychol. 32, 492-504. doi: 10.1037/ 0012-1649.32.3.492

Thornton, R. (2008). Why continuity. Nat. Lang. Linguist. Theory 26, 107-146.

Tomasello, M. (2000). The item-based nature of children's early syntactic development. Trends Cogn. Sci. 4, 156-163. doi: 10.1016/s1364-6613(00) 01462-5

Tomasello, M. (2003). Constructing a Language: A Usage-Based Theory of Language Acquisition. Cambridge, MA: Harvard University Press.

Tomasello, M. (2006). “Acquiring linguistic constructions," in Handbook of Child Psychology: Cognition, Perception, and Language, eds D. Kuhn and R. S. Siegler (New York: Wiley), 255-298.

Tsai, W. T. D. (1999). "The hows of why and the whys of how," in UCI Working Papers in Linguistics, Vol. 5, eds F. D. Gobbo and H. Hoshi (Irvine, CA: UC Irvine), 155-184.

Tsai, W. T. D. (2000). Weishenme wen zenmeyang, zenmeyang wen weishenme (The hows of why and whys of how) (in Chinese). Hanxue Yanjiu 18, 41-59.

Tsai, W. T. D. (2007). 'The hows of why and whys of how' revisited: on inner and outer adverbials in Chinese interrogative and reflexive sentences (in Chinese). Zhongguo Yuwen 3, 195-207.

Tsai, W. T. D. (2008). Left periphery and how-why alternations. J. East Asian Linguist. 17, 83-115. doi: 10.1007/s10831-008-9021-0

Wang, L. (1943). Zhongguo Xiandai Yufa (Grammar of Modern Chinese) (in Chinese). Beijing: The Commercial Press.

Xiao, Z. (2009). On the semantic and syntactic analysis of zenme ${ }_{1}$ and zenme 2 (in Chinese). Hanyu Xuexi 2, 44-49.

Yang, C., Crain, S., Berwick, R. C., Chomsky, N., and Bolhuis, J. J. (2017). The growth of language: universal grammar, experience, and principles of computation. Neurosci. Biobehav. Rev. 81, 103-119. doi: 10.1016/j.neubiorev. 2016.12.023

Zhu, D. (1982). Yufa Jiangyi (Lectures on Grammar) (in Chinese). Beijing: The Commercial Press.

Conflict of Interest: The authors declare that the research was conducted in the absence of any commercial or financial relationships that could be construed as a potential conflict of interest.

Copyright (c) $2020 \mathrm{Li}$ and Zhou. This is an open-access article distributed under the terms of the Creative Commons Attribution License (CC BY). The use, distribution or reproduction in other forums is permitted, provided the original author(s) and the copyright owner(s) are credited and that the original publication in this journal is cited, in accordance with accepted academic practice. No use, distribution or reproduction is permitted which does not comply with these terms. 


\section{APPENDIX A}

Test and filler sentences in Experiment 1: (1) to (4) were test sentences, and (5) to (8) were filler sentences.

(1) Hema zenme dai xiaogou hui jia?

Hippo how/why take dog return home

a. Manner reading: How did the hippo take the dog home?

b. Causal reading: Why did the hippo take the dog home?

(2) Maotouying zenme bang weinixiong zhao chongwu?

Owl how/why help Winnie the Pooh find pet

a. Manner reading: How did the owl help Winnie the Pooh find the pet?

b. Causal reading: Why did the owl help Winnie the Pooh find the pet?

(3) Meirenyu zenme gei xiaopangzi hua hudie?

Mermaid how/why for little fatty draw butterfly

a. Manner reading: How did the mermaid draw the butterfly for the little fatty?

b. Causal reading: Why did the mermaid draw the butterfly for the little fatty?

(4) Xiaoyu zenme ti qingwa cang baoxiang?

Fish how/why for frog hide treasure box

a. Manner reading: How did the fish hide the treasure box for the frog?

b. Causal reading: Why did the fish hide the treasure box for the frog?

(5) Dafeng chui fan le shenme?

Wind blow over ASP what

'What did the wind overturn?'

(6) Weini de chongwu shi shenme?

Winnie the Pooh POSSESSIVE pet be what

'What was Winnie the Pooh's pet?'

(7) Meirenyu jingchang zhong shenme?

Mermaid often plant what

'What did the mermaid often grow?'

(8) Baoxiang limian you shenme?

Treasure box inside have what

'What was inside the treasure box?'

\section{APPENDIX B}

Warm-up questions in both Experiment 1 and Experiment 2.

(1) Zhege pangpangde shi shenme dongwu?

This fat is what animal

What animal is this fat one?

(2) Zhege xiaoxiaode shi shenme dongwu?

This small is what animal

What animal is this small one?

(3) Zhege baisede wupin shi shenme?

This white object is what

What is this white object?

(4) Zhege yuanyuangde wupin shi shenme?

This round object is what

What is this round object? 


\section{APPENDIX C}

Test sentences in Experiment 2: (1) to (4) were presented to Group A, and (5) to (8) were presented to Group B. The same set of filler sentences as in Experiment 1 was presented to both groups.

(1) Hema hui zenme dai xiaogou hui jia? Hippo would how take dog return home 'How would the hippo take the dog home?'

(2) Maotouying hui zenme bang weinixiong zhao chongwu? Oowl would how help Winnie the Pooh find pet 'How would the owl help Winnie the Pooh find the pet?'

(3) Meirenyu hui zenme gei xiaopangzi hua hudie? Mermaid would how for little fatty draw butterfly 'How did the mermaid draw the butterfly for the little fatty?'

(4) Xiaoyu hui zenme ti qingwa cang baoxiang? Fish would how for frog hide treasure box 'How would the fish hide the treasure box for the frog?'

(5) Hema zenme hui dai xiaogou hui jia? Hippo why would take dog return home 'Why would the hippo take the dog home?'

(6) Maotouying zenme hui bang weinixiong zhao chongwu? Owl why would help Winnie the Pooh find pet 'Why would the owl help Winnie the Pooh find the pet?'

(7) Meirenyu zenme hui gei xiaopangzi hua hudie? Mermaid why would for little fatty draw butterfly 'Why would the mermaid draw the butterfly for the little fatty?'

(8) Xiaoyu zenme hui ti qingwa cang baoxiang? Fish why would for frog hide treasure box 'Why would the fish hide the treasure box for the frog?' 